\title{
Violência Contra a Mulher: o Desencontro entre os Gêneros
}

\author{
Violence against Women: the Mismatch between Genders \\ Violencia Contra la Mujer: el Desencuentro entre los Géneros
}

\author{
Rachel Moreno \\ Observatório da Mulher e Rede Mulher e Mídia \\ E-mail: rachelmoreno369@gmail.com
}

\section{Resumo}

A discussão sobre a violência de gênero tomou corpo desde 1979 , no $2^{\circ}$ Congresso da Mulher Paulista, e da fundação do SOS Mulher, em São Paulo, e se atualiza com atuação do movimento feminista, assim como com a constituição de políticas e equipamentos públicos voltados ao atendimento da questão. Este artigo aborda os problemas que surgem a partir da contradição nas expectativas de gênero com relação aos relacionamentos afetivos construídos de forma simbólica pela cultura vigente, e as dificuldades que as mulheres têm para romper com a situação de violência, mesmo contando com políticas e equipamentos públicos. Discute ainda a ampliação dos limites do conceito de violência, a possibilidade de sua articulação com os movimentos sociais, as dificuldades e limitações na expectativa e formação dos profissionais envolvidos neste atendimento, e aponta as oportunidades que aqui se abrem para o/as psicólogo/as.

Palavras-chave: violência de gênero; movimento feminista; políticas e equipamentos públicos; dificuldades de rompimento.

\section{Abstract}

The debate on gender violence has been consistent in Brazil since 1979, in the II Congress of Women from Sao Paulo, and since the foundation of SOS Women in Sao Paulo, being updated with the actions of the feminist movement and the development of public policies and equipment to deal with the question. This article presents the problems and difficulties that arise both from the contradiction in gender expectations constructed symbolically by our current culture regarding affective relationships and the difficulties that women have to break away from violence situations, even counting on public policies and equipment. It is also debated here the expansion of the limits, both of the concept of violence and of the possibility of its articulation with social movements. Finally, difficulties and limitations in the expectations and training of the professionals involved in this assistance are presented and discussed, pointing out opportunities that emerge for the psychologists.

Keywords: gender violence, feminist movement, public equipment and policies, difficulties in breaking up.

\section{Resumen}

La discusión de la violencia de género en Brasil tomó cuerpo desde 1979 , en el $2^{\circ}$ Congreso de la Mujer de Sao Paulo y con la fundación del SOS Mujer en SaoPaulo, actualizándose con la acción del movimiento feminista y con la constitución de políticas y equipos públicos de atención a la question. Este artículo aborda los problemas y las dificultades que surgen, tanto a partir de la contradicción en las expectativas de género en las relaciones afectivas construidas de forma simbólica por la cultura vigente, como de las dificultades que las mujeres tienen de romper con la situación de violencia, aun contando con políticas y equipos públicos. Discute también la ampliación de los límites, tanto del concepto de violencia como de la posibilidad de su articulación con los movimientos sociales. Finalmente, aborda las dificultades y limitaciones en la expectativa y formación de los profesionales involucrados en esta atención, y apunta hacia las oportunidades que se abren aquí para los psicólogos y las psicólogas.

Palabras claves: violencia de género, movimiento feminista, políticas y equipos públicos, dificultades de ruptura. 
O texto abaixo organiza e sintetiza a vivência que tive com a questão da violência de gênero, desde 1979, a partir do $2^{\circ}$ Congresso da Mulher Paulista, e da fundação do SOS Mulher, em São Paulo. Minha vivência se atualizou não só com a constante preocupação e com as denúncias do movimento feminista, como também com minha atuação profissional na coordenação técnica das duas casas-abrigo do Consórcio do $\mathrm{ABC}$ e no Projeto Santa Fé, que acolhe mães ou grávidas menores de idade.

\section{0 desencontro entre os gêneros}

Embora estejamos em pleno século XXI, os contos de fada e a nossa percepção da vivência dos mais velhos levaram as mulheres a acreditar em duas máximas relativas aos envolvimentos e compromissos afetivos. São elas: "Casaramse e foram felizes para sempre" e "O diálogo sustenta o amor, depois que termina a paixão". A realidade, porém, demonstra frequentemente outra sequência, que passa por namoro $\rightarrow$ paixão $\rightarrow$ casamento $\rightarrow$ diálogo $\rightarrow$ silêncio $\rightarrow$ "sacarolha" $\rightarrow$ gritos $\rightarrow$ adeus!

Já as expectativas masculinas passam hoje por outras dificuldades, nesta geração-transição masculina. Eles aceitam a participação da mulher no mundo, mas não a ponto de comprometer o seu próprio papel de líder, do qual hoje, de fato, só resta um resquício simbólico de sua "realeza" em seu lar doce lar. Afinal, o homem continua sendo predominantemente visto como "o rei em seu castelo".

A sociedade conspira e legitima, ao menos parcialmente, as aspirações femininas à equidade (nós, mulheres, estamos hoje em todos os lugares - escolas, faculdades, trabalho, rua, política); e, embora ainda não gozemos da igualdade de direitos, a questão de gênero já é transversal. Olhando ao redor, as mulheres percebem que a sociedade de certa forma conspira e legitima as suas aspirações. O salário e o emprego, que mínguam nestes tempos neoliberais, empurram os homens a aceitar o trabalho feminino (sem considerar ou perceber o aumento do número de famílias sustentadas exclusivamente por mulheres). As mulheres estão nas ruas, no transporte, nos aeroportos, no trabalho, na escola e nas faculdades. Isso faz com que o príncipe, já- não-mais-encantado, esteja só e nu. Ele é ainda o rei em seu castelo. Mas o mundo entra pela janela, pela TV, pelos vizinhos, pelo trabalho, pela independência financeira das mulheres, por todas as portas e janelas. Não é um reinado fácil.

Assim, depois de este super-homem aguentar o chacoalhar no ônibus ou trem durante um par de horas até chegar ao trabalho, de aguentar ao longo do dia o olhar desconfiado da chefia (quando tem emprego), de não se sentir valorizado durante todo o dia, de aguentar clientes chatos que só questionam e nada compram, de chacoalhar novamente no transporte lotado, finalmente chega ao boteco perto de casa e toma uma com os amigos para relaxar. Quando chega em casa, já um tanto mais relaxado, tem que ouvir a mulher reclamar da hora em que ele finalmente chegou, ou do bafo de álcool - logo ali, onde ele é o rei do castelo, onde "ninguém mete a colher", então ele descarrega todas as frustrações do dia e bate na mulher.

Tomamos contato de forma mais efetiva com questões relativas à condição das mulheres na sociedade, que é na verdade a válvula de escape de manutenção do sistema, em 1979 no $2^{\circ}$ Congresso da Mulher Paulista. Foi nesse momento que a questão foi claramente percebida e eleita como a de maior prioridade pela plenária de mulheres lá presentes. $\mathrm{Na}$ época, ainda sob a Ditadura, as organizações de esquerda consideravam que, antes de qualquer coisa, devíamos derrubar a ditadura e fazer a revolução. Depois disso é que trataríamos da elaboração e implantação de políticas públicas que atendessem às necessidades da mulher. Mas como dizer isso a uma mulher que apanha cotidianamente do marido? Assim, em atenção às demandas das mulheres, e depois de um grupo de 
feministas refletir sobre questões contempladas pelas leis e políticas públicas, nasce em São Paulo o primeiro SOS Mulher, no dia 10 de outubro de 1979.

Ainda sob o clima da ditadura militar, sem saber bem quem as procuraria, e que risco isso representaria, as feministas de São Paulo se organizam e abrem as portas para o atendimento de mulheres vítimas de violência, com plantões em que se revezavam grupos de militantes de variadas formações, aos quais pouco tempo depois foram se agregando profissionais do Direito (da OAB Mulher) para, também militantemente, auxiliarem essas vítimas a procurarem defesa institucional para o que sofriam. No entanto, as delegacias de polícia não estavam preparadas para dar importância a essas vítimas, nem tampouco entender o que se passava, dando por vezes razão ao agressor.

\section{As várias faces da violência}

Essa violência, posteriormente descobrimos, tinha várias faces. E atingia todas as classes sociais - como foi possível perceber no dia do lançamento do SOS Mulher, em frente ao Teatro Municipal, quando a esposa de um conhecido professor universitário denunciou publicamente a agressão que sofreu, "pedagogicamente" segundo o seu autor, já que ela se recusava, em função dos compromissos profissionais que ela tinha, a acompanhá-lo em uma viagem.
E, no plantão aberto, fomos descobrindo a violência doméstica - a saber, física, psicológica e patrimonial; o assédio sexual e o estupro na rua, ou mesmo em casa; o assédio moral e sexual no trabalho. Sem contar as diversas formas de discriminação, que representam a face mais disfarçada (ou culturalmente integrada) da violência de gênero. Na época, sentimo-nos tentadas a classificar todos os tipos de discriminação de gênero como sendo uma forma de violência.

\section{Onde e quando ocorre a violência de gênero}

Em caso de perigo, a tendência natural das mulheres ameaçadas ou sentindo-se inseguras seria correr para perto de pessoas conhecidas, amigos ou parentes, em busca de proteção e solidariedade. Entretanto, nos demos conta, a julgar pelos índices históricos, que as mulheres não estão seguras nem em sua própria casa, já que a violência doméstica é a que ultrapassa todos os índices dos demais tipos de violência ${ }^{1}$. Mais recentemente, soubemos que em festas ${ }^{2}$, ao se sentirem estranhas devido ao efeito de alguma bebida que tenham tomado, as estudantes universitárias por medida de cautela aproximavam-se de algum amigo ou conhecido, para se sentirem mais protegidas. Porém, muitas delas perceberam, ao acordar tempo depois, que haviam sido vítimas de um estupro, coletivo ou não, sob o efeito do "boa noite cinderela" ou similar, adicionado à sua bebida com a cumplicidade de seu "amigo".

1 Para maiores informaç̃es, consultar Violência contra a mulher (2017); Enfrentamento de todas as formas de violência contra as mulheres (2017).

2 Para maiores informações, consultar Assédio contra mulheres. A violência que é rotina nas noites (2016); Abordagens violentas na balada revoltam mulheres (2013); Trio é condenado por estuprar adolescente em balada de Santos (2017). 


\section{A reação e encaminhamento}

No início do SOS Mulher, em fins de 1970, quando instruíamos as queixosas a registrar um boletim de ocorrência pela violência doméstica sofrida reiteradas vezes e da qual tinham sido vítimas, as mulheres voltavam para nos relatar a atitude do delegado. Alguns desses relatos são descritos na sequência.

Dona Maria, a Sra. vai denunciar o seu marido - um homem bom, trabalhador?!

Vá para casa, dona Maria, capriche no tempero do feijão, compre uma camisola nova, que tudo ficará bem...

Quando a queixa se referia a um estupro ou um assédio sexual sofrido na rua, o comentário do delegado era:

Mas a senhora estava sozinha na rua, às 10 da noite?!?

Ou ainda, eventualmente:

Mas... vestida desse jeito, com essa saiazinha???

Ou seja, a vítima era transformada em culpada pela violência sofrida. Mais recentemente, em uma palestra em uma universidade do Canadá, um delegado teria declarado que o jeito como as mulheres se vestem é que seria o principal responsável pelos estupros e demais manifestações de assédio ${ }^{3}$.

Imediatamente, no mundo todo, num movimento iniciado pelas ativistas do Femen ${ }^{4}$, mulheres saíram à rua em protesto contra uma sociedade dominada pelos homens, fazendo topless e com o peito pintado com dizeres sinalizando que as mulheres podem se vestir como quiserem, sem que isso seja lido como um convite à violência sexual.

Campanhas mais recentes, como a "Chega de fiu-fiu" passaram a dar visibilidade ao assédio nos espaços públicos como algo que incomoda as mulheres. Em algumas manifestações de protesto, as mulheres chegaram a distribuir apitos ou alfinetes de segurança, sugerindo que assim denunciariam ou afastariam os assediadores nos transportes públicos.

Também no local de trabalho, a violência de gênero é perpetrada contra mulheres, não sendo pouco frequentes o assédio moral ou mesmo o assédio sexual. Entretanto, nos últimos tempos, apesar de terem aumentado as denúncias de violência contra a mulher (estupro, assédio, violência doméstica e até feminicídio), diminuíram os registros de assédio no trabalho. Em tempos de desemprego crescente, é lógico supor que, por temor às consequências, as mulheres prefiram não denunciar o assédio de um superior, ou mesmo de um colega.

Mas estamos falando de assédio e deixando de lado outras formas de violência, já tão naturalizadas, que não são mais denunciadas como tal. Ou não será violência a discriminação que faz com que as mulheres no Brasil ganhem $70 \%$ da massa salarial dos homens - ainda mais agora, que estamos em todas as profissões e espaços de conhecimento? Quão longe ainda estamos da

3 Para maiores informações, consultar A brief history of women's protests (2011); "SlutWalk" marches sparked by Toronto officer's remarks (2011).

4 Para maiores informações, consultar Femen (2013).

5 "Chega de fiu-fiu" é uma campanha contra o assédio sexual em espaços públicos, nascida em 24 de julho 2013 lançada pelo Think Olga. Inicialmente, foram publicadas ilustrações com mensagens de repúdio a esse tipo de violência. As imagens foram compartilhadas por milhares de pessoas nas redes sociais, gerando uma resposta tão positiva, que acabou sendo o início de um grande movimento social contra o assédio em locais públicos. 
Islândia, que acabou de proibir a diferença salarial entre homens e mulheres, obrigando as empresas a fornecer os dados ao Estado, que por sua vez fiscaliza e multa as empresas eventualmente transgressoras. Ou, ainda, não será entre nós uma manifestação de violência "naturalizada" o chamado "teto de vidro", que nos faz escassear nos cargos superiores, apesar de nos sairmos tão bem em todos os lugares onde nos propomos a trabalhar?

\section{A naturalização da violência de gênero}

Houve um tempo em que os livros escolares infantis apresentavam sempre a "mamãe" como uma figura feminina de avental, preferencialmente sujo de ovo, se despedindo do "papai" de terno e gravata e pasta na mão, abrindo-lhe a porta da rua. Esses estereótipos grosseiros - que sinalizam os papéis atribuídos a homens e mulheres - foram eliminados há algum tempo. Mas sabemos que a maioria dos homens autores de violência doméstica vivenciaram cenas de violência, quando crianças, entre seus pais, e ficaram inicialmente traumatizados. E não havia lugar adequado para discutir essa questão. Crescendo e passado o trauma e não tendo com quem discutilo criticamente, o homem tende a naturalizar as práticas domésticas violentas e a replicar as cenas quando adulto.

Diante desses fatos e situações, evidenciou-se a necessidade de se incluir a discussão das questões de gênero no Plano Nacional de Educação (PNE). Educadores e educadoras ouviram as vozes de uma parte da sociedade - plural, transformadora, contemporânea -, e não podemos deixar de valorizar aqui o papel das feministas.

E quase conseguimos. Entretanto, a bancada evangélica, aliada aos parlamentares mais conservadores, fez uma intensa campanha pela exclusão da temática no $\mathrm{PNE}$, alegando que tal projeto pedagógico, que rebatizaram de “ideologia de gênero", estimularia a pedofilia. E conseguiram derrubá-lo, em nível nacional, estadual e municipal. Hoje, essa mesma bancada estimula os pais a denunciarem as escolas e os professores que porventura se atrevam a incluir tal discussão nas salas de aula. E, assim, não permitem que se discutam essas questões, assim como a discriminação, o bullying nas escolas, passando por cima inclusive da "liberdade de cátedra".

Para além disso, a TV (e a mídia em geral) representa uma poderosa educadora informal. As crianças, assim como os adultos, aprendem nela a ler, a beijar, a reconhecer os padrões e comportamentos socialmente valorizados e os não valorizados. $\mathrm{E}$, na mídia, a violência de gênero se banaliza - de tanto ser reiterada numa série de contextos sem nenhuma abordagem crítica. Ou, no caso em que um dos envolvidos no drama exposto no noticiário seja famoso e atraia a audiência, espetaculariza-se o fato noticioso, graças à exposição reiterada e abundante do caso, sem maiores cuidados ou preocupações éticas ou pedagógicas.

Com essas duas atitudes, reforçam e naturalizam a violência de gênero na sociedade, em vez de combatê-la e tratá-la de forma mais crítica e menos dramatúrgica.

\section{0 amor idealizado}

Durante a adolescência, e sem nenhuma formação em educação sexual, os jovens tendem a confundir o desejo sexual com amor. Outro atributo dito "feminino" que se estimula intensamente é o modelo, edulcorado pela cultura conservadora de "amor materno", que leva as mães a renunciarem à própria vida e às suas necessidades, para comprazer as demandas de seus filhos.

Não se trata de negar que a defesa da prole, pela mãe, seja algo natural, tanto na nossa como em 
muitas outras espécies. Mas, entre nós, humanos, imersos na contemporaneidade tecnológica dos poderosos conglomerados midiáticos e das redes sociais, esta atitude se estabelece frequentemente diante de manhas e desejos fúteis - expressos ou estimulados pela publicidade e pelas inserções dramatúrgicas nas redes que, no caso de nosso país, com uma mídia centralizada e bastante dependente dos recursos dos anunciantes, são hegemônicas e direcionadoras dos conteúdos.

E essa relação é frequentemente absorvida no contexto familiar e estende-se ao companheiro, marido ou a quem quer que se tenha "eleito" para estar ao lado da mulher "até que a morte os separe". E assim vivemos uma situação de violência machista estrutural: não se estabelece qualquer contraditório diante deste "modelo", nem se tenta abolir - ou simplesmente não se estimula - qualquer recurso que possa reverter em maior sensibilização dos diversos grupos sociais, ou preveni-los com relação às violências de gênero tratadas de forma estereotipada nas diferentes mídias, assim como frente à doutrinação patriarcal nelas difundidas.

\section{0 que fazer?}

A luta das mulheres contra a violência de gênero se organizou desde 1979. Ganhou ímpeto e visibilidade, em São Paulo e no Brasil, com as manifestações de protesto contra o assassinato de Eliane de Grammont, no dia 3 de junho de 2002, por seu ex-marido, Lindomar Castilho. As manifestações foram promovidas pelo SOS Mulher e divulgadas inclusive na TV Globo, em respeito à Helena de Grammont, irmã da Eliane, que lá trabalhava.

Quando voltamos a ter eleições diretas, o SOS Mulher foi procurado pelos partidos políticos - PT e PMDB. Diante da visibilidade que havíamos ganho na mídia, que divulgava todas as nossas denúncias e casos exemplares (provavelmente porque achava que as notícias sangrentas vendiam jornal e programas), esses dois partidos vieram nos perguntar o que de fato queríamos.

Cheias de esperança, expusemos a situação e as dificuldades que enfrentávamos para resolver os problemas, declarando que queríamos mudar a situação de violência vivenciada pelas mulheres. Sabendo das críticas à total ausência de políticas públicas para combater a escalada de violência contra a mulher, e das manifestações públicas promovidas pelo movimento de mulheres, Franco Montoro, eleito em 1982 governador do estado de São Paulo, lança em 1985 a primeira delegacia da mulher, chefiada pela Delegada Rose (Marques, 2015). Posteriormente, o SOS Mulher e a Delegacia da Mulher passaram a ser implementadas em diversos outros estados.
Depois disso, no governo de Luiza Erundina, candidata a Prefeitura de São Paulo em 1988 pelo PT, inaugura-se a Casa Eliane de Grammont o primeiro Centro de Referência para mulheres vítimas de violência em São Paulo e no país (Matsuda, 2015). Mais tarde, esses centros se multiplicam, e hoje dividem o espaço público com Casas-Abrigo, de endereço sigiloso, onde as mulheres podem se abrigar com os seus filhos, enquanto reorganizam sua condição buscando autonomia financeira, escola para os filhos, etc.

Em 1996, aprova-se finalmente a Lei Maria da Penha, com medidas protetivas às vítimas de violência. Em 2014, aprova-se a lei do Feminicídio, e desde 2014 o Governo Federal começa a construir a Casa da Mulher Brasileira - uma em cada capital, juntando num mesmo espaço todas as demandas e serviços - e a bancar por dois anos o seu funcionamento. Infelizmente, a Casa de São Paulo, já pronta há dois anos, não é inaugurada pelo atual prefeito Dória, por falta de ligação da luz e água.

Para além dessas políticas públicas, estão disponíveis os serviços de Ligue 0800 - um número em que a mulher vítima de violência liga para saber onde fica o equipamento mais próximo de onde ela está, para que possa prestar queixa ou se abrigar. Considerando que o primeiro lugar onde a mulher vítima de violência costuma pedir ajuda é no Posto de Saúde, quando está machucada, já há alguns anos que a Saúde tem que notificar os casos de violência que atende. $\mathrm{E}$, finalmente, a 
Assistência Social, o Conselho Tutelar, o Conselhos de Defesa dos Direitos da Mulher, a Defensoria Pública, entre outros, preenchem também certo papel no que tange à assistência às mulheres em situação de violência.

Contudo, estes equipamentos estão atualmente sucateados - tanto no estado como no município de São Paulo, conforme denúncia do movimento feminista e do Conselho de Políticas para Mulheres de São Paulo. E a violência de gênero - válvula de escape do sistema capitalista e patriarcal - atinge índices alarmantes no país, materializando as relações sociais de poder, e concretizando o poder patriarcal sobre a mulher, que a atinge em vários contextos de sua vida.

\section{Dimensões do Problema}

Segundo o Instituto de Pesquisa Econômica Aplicada (IPEA), em 2015, 4.621 mulheres foram assassinadas no Brasil, o que corresponde a uma taxa de 4,5 mortes para cada 100 mil mulheres. É importante também notar que há diferença nesse resultado, se o perfil de mulheres vítimas de violência for estratificado por raça/cor: enquanto a mortalidade de mulheres não negras sofreu uma redução de 7,4\% entre 2005 e 2015, atingindo 3,1 mortes para cada $100 \mathrm{mil}$ (ou seja, abaixo da média nacional), a mortalidade de mulheres negras aumentou 22\% no mesmo período, chegando à taxa de 5,2 mortes para cada 100 mil - acima, portanto, da média nacional.

Os dados apresentados revelam um quadro grave, e indicam também que muitas dessas mortes poderiam ter sido evitadas. Em inúmeros casos, até chegar a ser vítima de uma violência fatal, essa mulher é antes vítima de uma série de outras violências de gênero, como bem especifica a Lei Maria da Penha (Lei 11.340/06): o plantonista da delegacia de polícia que não registra a agressão; os vizinhos que não intervêm, por achar que "não é da minha conta"; a família que acredita ser "coisa de casal”. Além da violência física, também cresce a violência psicológica, patrimonial ou sexual, em um movimento de agravamento crescente que muitas vezes antecede e sinaliza o desfecho fatal. Em 2014, a mesma pesquisa estimou que no mínimo 527 mil pessoas são estupradas por ano no Brasil, e que destes casos apenas $10 \%$ chegam ao conhecimento da polícia.
Os registros do Sistema de Informação de Agravos de Notificação (SINAN), que é alimentado principalmente pela notificação e investigação de casos de doenças e agravos de notificação compulsória, demonstram que o perfil das mulheres vitimadas pela violência doméstica é composto por mulheres em geral com baixa escolaridade (89\%). A pesquisa também aponta que do total $70 \%$ são crianças e adolescentes, sendo "As consequências, em termos psicológicos, para esses garotos e garotas são devastadoras, uma vez que o processo de formação da autoestima - que se dá exatamente nessa fase - estará comprometido, ocasionando inúmeras vicissitudes nos relacionamentos sociais desses indivíduos".

Em metade das ocorrências envolvendo menores, existe um histórico de estupros anteriores. Para o diretor do IPEA, "o estudo reflete uma ideologia patriarcal e machista que coloca a mulher como objeto de desejo e propriedade". Ainda de acordo com a Nota Técnica, 24,1\% dos agressores das crianças são os próprios pais ou padrastos, e 32,2\% são amigos ou conhecidos da vítima. O indivíduo desconhecido passa a se configurar paulatinamente como principal autor do estupro à medida que a idade da vítima aumenta. Na fase adulta, este responde por $60,5 \%$ dos casos.

Em geral, segundo pesquisas do IPEA, IBGE, Fundação Perseu Abramo,70\% dos estupros são cometidos por parentes, namorados ou amigos e conhecidos da vítima. Esses números indicam que o principal inimigo está dentro de casa, e que a violência nasce no interior dos lares. 


\section{Demandas Hoje}

A legislação deve ser vista como instrumento de gestão para que se construam compromissos éticos, comportamentais e políticos. A ampliação e o aprimoramento da rede de atendimento à mulher são fundamentais não apenas para o melhor acompanhamento das vítimas, mas também pelo seu papel na prevenção da violência contra a mulher. Um ponto importante a ser enfatizado é a necessidade de que essa rede possa ser acessada pelo Sistema de Saúde, e não apenas pelo Sistema de Justiça Criminal. Muitas mulheres passam várias vezes pelo Sistema de Saúde antes de chegarem a uma delegacia ou a um juizado, e muitas nunca chegam. Em 2016, na pesquisa Visível e Invisível: a Vitimização de Mulheres no Brasil, encomendada ao Datafolha pelo Fórum Brasileiro de Segurança Pública, com representatividade nacional, aferiu-se que $29 \%$ das mulheres brasileiras relataram ter sofrido algum tipo de violência, sendo que apenas $11 \%$ dessas mulheres procuraram a Delegacia da Mulher. A pesquisa também indicou que em $43 \%$ dos casos a agressão mais grave foi no seu próprio domicílio.

Para que essa rede de atendimento funcione plenamente, é necessário que ela consiga oferecer opções reais para que a mulher possa sair do ciclo de violência - que a vítima sozinha, sem ajuda de profissionais, dificilmente consegue romper. A Pesquisa de Condições Socioeconômicas e Violência Doméstica e Familiar contra a Mulher (PCSVDF Mulher), realizada em 2016 pelo Instituto Maria da Penha (IMP) em parceria com a Universidade Federal do Ceará e o Instituto para Estudos Avançados de Toulouse, na França, apresenta uma radiografia da violência de gênero no Nordeste brasileiro, que reforça a necessidade de se desenvolverem ações e programas multissetoriais e multidisciplinares (IPEA, 2017).

Mas, para além da ampliação e da melhoria da estrutura de atendimento, urge implementar medidas que aumentem a sensibilidade e a formação para reconhecimento analítico e atendimento criterioso do problema para, assim, conseguir preveni-lo. Neste sentido, a discussão das "Questões de gênero" nas escolas é de fundamental importância em termos preventivos para todos, mulheres e homens, e ainda mais diante da constatação da grande incidência de agressores que vivenciam a violência doméstica em seus lares na infância.

Os dados sobre a violência contra a mulher são absurdos e exigem de todos uma crescente consciência do seu significado e de como atuar para mudá-los. A escola como espaço privilegiado de formação e socialização precisa acolher essa discussão, ajudando os estudantes a compreender esse tema em toda a sua complexidade e extensão, implicando-os como possíveis sujeitos transformadores. Isso pode começar dentro da escola com a proposição de uma vivência cotidiana que reflita um compromisso efetivo com o respeito a todas as mulheres em tudo aquilo que elas mesmas reconhecem como aspectos marcantes de sua identidade.

Mas, diante da cruzada conservadora e bemsucedida das bancadas evangélicas nas três câmaras legislativas contra o que decidiram batizar de "ideologia de gênero", outras questões, além das "Questões de Gênero", deveriam alcançar as escolas, como a discussão da Lei Maria da Penha, ou de outros aspectos que foquem particularmente a prática de bullying e a igualdade entre os sexos, bem como a discriminação racial.

São também necessários programas de TV que discutam essas questões, além de cuidados específicos para não reproduzir, banalizar e naturalizar a violência de gênero, os preconceitos e estereótipos. Seria importante um Ligue 0800, que pudesse acolher as denúncias e orientar, além de apontar as limitações do endereço eletrônico. Urge também utilizar a grande mídia para promover campanhas sobre a violência contra a mulher, como consta, de forma explícita, no último parágrafo da Lei Maria da Penha. É também necessário aumentar o alcance da estrutura de atendimento existente, ante o seu funcionamento e a demanda que desperta. 
Fundamental ainda seria a formação adequada e/ou sensibilização necessária dos diversos profissionais que lidam com a violência de gênero. Isso deveria ainda garantir a sua inclusão no currículo da universidade - na área de Saúde, Educação, Assistência Social, Segurança Pública (além de Conselhos Tutelares, Conselhos de Direitos), Enfermagem, Psicologia, Medicina, etc.

Muito se ganharia se novos profissionais com capacitação específica fossem incorporados em escolas, postos de saúde, pronto-socorros, entre outras unidades, pois garantiria um atendimento integral e intercruzariam conhecimentos e percepções (saúde, psicologia, feminismo, estatísticas, etc.), de modo a complementar a visão que se tem do problema, de como abordá-lo e de como minimizá-lo eficazmente.

Mostram-se também necessários maior agilidade e acompanhamento do caso pela Delegacia da Mulher, construção e/ou fortalecimento de uma estrutura de apoio para a mulher que quer ou precisa sair de casa (emprego, auxílio aluguel), estrutura de acolhimento da família (o que fazer com os filhos traumatizados), multiplicação de delegacias 24 horas (o Estado de São Paulo só possui uma - e sabe-se que a violência doméstica ocorre mais frequentemente à noite e aos fins de semana, além de ocorrer em todo o estado, e não apenas na capital). Além disso, é preciso ampliar e multiplicar programas educativos e terapêuticos para homens autores de violência contra as mulheres, oferecendo um espaço de reflexão e discussão na busca de resgatar os outros bons aspectos que os levaram ao envolvimento afetivo e à constituição de uma família.

Finalmente, enriqueceria muito o processo se as políticas públicas pudessem ter uma integração do movimento social, de modo a dar suporte e a acolher as mulheres, em suas redes, depois de sua saída da Casa-Abrigo.

\section{Círculo Vicioso \& 0 Papel do/a Psicólogo/a}

Em um primeiro momento, é difícil entender por que, depois de exposta à violência, a ponto de vir se queixar e/ou se tratar, a mulher frequentemente volta para casa, eventualmente retira a queixa (enquanto isso era possível) e, pouco tempo depois, está vivendo novamente uma situação de violência, com o fato adicional: a cada episódio, a intensidade da violência aumenta.

Aos poucos, fomos descobrindo o círculo vicioso que se estabelece entre o casal, e que prolonga a vivência da mulher na situação de violência. Sem entendê-lo, a reação de quem atende a uma vítima de violência é de estranheza - como ocorreu com as atendentes na Delegacia da Mulher, de enfermagem e outros. O esquema seria o seguinte: violência $\rightarrow$ pedido de desculpas $\rightarrow$ reconciliação $\rightarrow$ lua de mel $\rightarrow$ novamente o silêncio $\rightarrow$ desentendimento $\rightarrow$ violência maior.

A seguir, há trechos contendo depoimentos de pessoas que acompanharam as agressões sofridas por Telma, assassinada pelo marido.

"Ela já tinha sido agredida várias vezes, eu vi. Ela podia ter ido embora, mas acho que ela gostava dele.
Nós, como família, falamos pra ela: 'vem embora, larga tudo e vem embora'. Olha aí o que deu.",conta o padrinho de Telma.

Em outra briga do casal, Telma chegou a pedir ajuda à polícia. Quem atendeu à ocorrência foi o capitão da PM Fábio Schultze: "Ela havia sido agredida por ele e apresentava um corte na cabeça. A equipe chegou no local e afirmou que ela possuía alguns hematomas, um corte e que tinha sido vitima de socos na região da cabeça".

Telma acabou não registrando a queixa contra o marido. Agora, seu assassinato está sendo investigado pela Polícia Civil de Suzano.

Pesa, neste círculo vicioso, a dificuldade de imaginar a vida sem o parceiro eleito, o impacto que a separação gera nos filhos, os eventuais problemas na perspectiva de uma nova construção de autonomia, assim como pesam o pedido de perdão, as juras de amor renovadas, a breve lua de mel e o período de paz.

Uma hora, ele é incrivel. Na outra, agressivo, mas logo cerca você de carinhos e declarações 
de amor, tentando limpar a barra pelo mal que causou. Agressores são cruéis, mas têm a capacidade de ser generosos e atenciosos, o que torna mais difícil identificá-los. Por isso, livrar-se de um relacionamento abusivo é tão complicado. (Guimarães \& Prado, 2017, página da web).

Ele fez isso porque a gente já não convivia bem dentro de casa e eu queria que a gente se separasse. Já tinha sido agredida por ele várias vezes. A gente acredita que vai mudar, que vai melhorar e não melhora", relata outra vítima de violência doméstica.

Tem picos, as desculpas, declarações. Cheguei a duvidar de mim mesma. Ele dizia que eu era ciumenta, louca, exagerada. Eu sempre ficava com o peso da culpa. E, quando a poeira baixava, vinham as promessas de uma vida melhor, mas duravam pouco....

Cabe à(o) psicóloga(o), antes de mais nada, garantir a receptividade e empatia. A mulher não pode se sentir julgada e/ou criticada de alguma forma, por sua reincidência; ela precisa saber que será acolhida. Cabe fazê-la perceber o círculo vicioso de comportamento que se dá em etapas. E, sobretudo, apoiar, entender, ajudar a mulher vítima de violência doméstica para que supere a situação e os temores.

Esse acolhimento pode alternar momento de conversa individual, com discussão/atendimento em grupo. A vivência comum e os diversos estágios de percepção desses mecanismos costumam ser de grande valia para a reflexão coletiva.

\section{Os Homens}

Há alguns anos, no Coletivo Feminista de Sexualidade e Saúde, formou-se um grupo reflexivo sobre violência de gênero para homens autores de violência contra a mulher, que trocavam um serviço comunitário, a que tivessem sido condenados (pena leve) por uma frequência semanal neste grupo terapêutico durante seis meses.

Tive a oportunidade de acompanhar um dos grupos em seu início, e de conversar com alguns dos participantes ao fim dos seis meses.
A diferença foi marcante: eles passavam de "vítimas incompreendidas" a excelentes multiplicadores de uma nova maneira de ver e vivenciar as relações entre os sexos.

Tais grupos passaram a existir no ABC Paulista e começam a se multiplicar em outros municípios, e hoje são implementados em Itaquaquecetuba. Representam também um espaço de trabalho bastante interessante para psicólogos.

\section{As Crianças}

$\mathrm{Na}$ casa-abrigo de mulheres vítimas de violência, as mulheres ali ficam por um tempo com os seus filhos. Além de irem à escola mais próxima, existem profissionais se ocupando das atividades dessas crianças durante o dia.

A atenção psicológica pode ser relevante neste estágio, e por vezes o contato com um psicólogo pode ser uma referência importante de homem não violento para essas crianças. Seria de fundamental importância, a título de formação e prevenção, se discutissem na sala de aula questões sobre preconceitos e estereótipos em relação às meninas e às mulheres que geram a violência de gênero (como o projeto Quem ama, abraça, no município de Santo André, ao qual deveria juntarse a discussão sobre direitos humanos, equidade de gênero e cidadania).

Nos meios de comunicação, seria fundamental se prestar atenção à reprodução de estereótipos e preconceitos; não banalizar a violência; praticar o sexo responsável (incluindo uso de preservativos); discutir temas contemporâneos; democratizar a 
mídia e lutar pela pluralidade e pela inclusão de um espaço para o movimento social no espectro e/ou na programação; revisar a programação, de modo a incluir programas específicos; e ter um olhar crítico sobre a programação atual (conteúdo, forma);
Finalmente, incluir um curso de Educação para a Leitura Crítica da Mídia, de modo a desenvolver mecanismos de percepção e análise crítica das intenções e insuficiências da comunicação, como existe no Canadá e em outros países.

\section{Outras Discussões}

Como já fora mencionado, recentemente novas campanhas têm surgido, abordando novas formas de caracterização da violência de gênero. Dentro desse rol, a campanha "Chega de fiu-fiu" discute o assédio no espaço público. Mais recentemente, houve pressão no sentido de melhor adequar a lei a respectiva punição, refletindo uma graduação mais justa entre o simples atentado ao pudor e o estupro - como no caso bastante discutido do homem que ejaculou no pescoço de uma passageira semiadormecida dentro do ônibus.

A falta de punição adequada tem estimulado o que muitos convencionaram chamar de "cultura da violência de gênero". Na sequência, são descritos casos em que o agressor acabou sendo absolvido.

Um homem agrediu a própria filh a de 13 anos com fios elétricos e cortou seus cabelos como forma 'de proteção'. O motivo? Ela não era mais virgem. Ele foi absolvido pelo juiz que garantiu que a conduta não era criminosa, mas um 'exercício do direito de correção'.

Outro homem foi detido após ejacular em uma mulher semi adormecida dentro de um ônibus na Avenida Paulista. Ele foi liberado sob o argumento de que 'não houve constrangimento'. No dia seguinte, o mesmo homem foi flagrado esfregando o pênis em outra mulher dentro do transporte público. Era a $17^{a}$ passagem dele pela delegacia por situações similares.

O jovem estudante de medicina é acusado de estupro. Ele foi absolvido após o juiz justificar sua decisão com base na 'inconsistência das declarações da ofendida'. O mesmo estudante também é denunciado por outros seis casos de violência sexual.

\section{A dificuldade em julgar crimes de gênero}

Para Gabriela Mansur, coordenadora do Núcleo de Combate à Violência contra a Mulher do Ministério Público de São Paulo, o Brasil é um país conservador e tem vivido, nos últimos tempos, uma crise econômica, democrática e de violência que se reflete nos altos índices de crimes de gênero e como os casos repercutem. A promotora argumenta:

O conservadorismo não está contra os direitos das mulheres, mas ele não se preocupa em fazer valer direitos conquistados pelos movimentos sociais e que são necessários para se evitar a violência. Tanto é verdade que hoje temos um desmantelamento das políticas para as mulheres. E isso reflete muito sobre o fato de que nem ao menos podemos discutir o assunto em alguns órgãos."

Cabe também formular, de maneira mais universal, normas e procedimentos contra o assédio moral e sexual no ambiente de trabalho. Nesses casos, cada categoria profissional tem definido isoladamente suas normas e seus procedimentos.

Finalmente, cabe retomar a discussão sobre se toda forma de discriminação e perda de 
direitos pode ser caracterizada como forma de violência. Neste caso seriam formas de violência as mudanças das regras que visariam cortar o pagamento de licença-maternidade, a redução da diferença na aposentadoria das mulheres (que acumulam a dupla jornada de trabalho, incluindo a doméstica) penalizando-as mais do que já penaliza todos os trabalhadores, a impunidade que termina reforçando o que muitas já chamam de "cultura do estupro"?

A inclusão efetiva da igualdade de direitos de homens e mulheres na Carta da ONU, documento lançado em 1945 que criou as Nações Unidas, foi fruto da insistência de diplomatas latinoamericanas lideradas pela cientista brasileira Bertha Lutz, que enfrentou forte oposição das delegações norte-americana e britânica.

A diferença salarial entre homens e mulheres (as mulheres ganham aproximadamente $70 \%$ da massa salarial dos homens no Brasil), não fiscalizando ou respeitando a demanda de "a trabalho igual, salário igual”, seria outra forma de violência ou simples superexploração? Seria a superexploração uma forma de violência?

Este 26 de outubro se tornou público em Genebra o Global Gender Gap de 2015, Informe que elabora, a cada ano, desde 2006, o Fórum Econômico Mundial, que mede a diferença de gênero no mundo em 4 áreas: Oportunidades Econômicas, Empoderamento Político, Educação e Saúde. No informe deste ano (2016) - que inclui 144 países, se atrasou em mais de 50 anos o tempo necessário às mulheres conseguirem igualar as condições econômicas dos homens. Dos 118 anos que se calculava seriam necessários em 2015 (até o ano de 2.133), agora se projetou que haverá que esperar 170 anos (ou seja, esperar até o ano de 2.186) para chegar a essa igualdade."(Global Gender Gap 2015).

Diante dessa perspectiva tão distante, em fins de 2017, na Islândia, as mulheres pararam de trabalhar, antes do fim regulamentar da jornada de trabalho (às 13,45h), afirmando que o salário que recebiam só pagava efetivamente este período encurtado. Hoje, na Islândia, a igualdade salarial entre homens e mulheres é lei (veja transcrição da matéria do Último Segundo, 2018); e a Ministra do Trabalho exige das empresas a entrega de dados e informações que lhe permitem fiscalizar a efetiva igualdade salarial, e penalizar quem não a cumprir.

Também em Barcelona e na França, a igualdade de gênero foi colocada em discussão .

Todo trabalho merece um salário". Com este slogan o Coletivo Feminista "Les Glorieuses" (As Gloriosas) fez uma chamada para o francês para que, no dia 7 de novembro de 2018, às 16,34 horas, (as mulheres) parassem de trabalhar. O Instituto Catalão de Mulheres explicou no Parlamento que os meios de comunicação, a coeducação e a participação das entidades são os eixos prioritários de seu trabalho para avançar rumo à equidade de gênero. Propostas de medidas e ações positivas e realistas. Essa foi a mesa de diálogo com representação paritária de quatro empresas e organizações que revelaram seus êxitos e propostas pela igualdade. Foi moderada por Sonia Ruiz Garcia, chefe do Departamento de transversalidade de Gênero da Região Metropolitana de Barcelona. Também se colheram as sugestões da doutora Cristina Sánchez Miret e do diretor na Espanha da OIT.

Também foi discutido como lidar com o assédio online contra mulheres jornalistas, garantindo-lhes segurança e liberdade de expressão, como debatido em abril de 2017, em um painel no Festival Internacional de Jornalismo, na Itália. Segundo pesquisa realizada, descobriu-se que as mulheres jornalistas sofrem aproximadamente três vezes mais abusos do que seus colegas masculinos, como relatado por Ricchiardi (2017), "Quando as mulheres jornalistas são o objetivo, o assédio online transforma-se rapidamente em ameaças e ódio sexualizado, e com uma frequência muito maior do que aos homens". Ele ainda acrescenta que "As mulheres são mais propensas a ser objeto da violência sexual e física online" 
Mas talvez aí estejamos nos distanciando da discussão mais restrita às manifestações de violência de gênero física, psicológica, patrimonial e simbólica. Fiquemos, portanto, nos limites desta discussão, bem como no objetivo que a motivou.

Com este texto, pretendíamos compartilhar as informações mais relevantes em relação ao tema com o/as profissionais e estudantes de nossa área de atuação (Psicologia), e agregar ao tema conhecimentos acerca da diversidade de práticas na promoção da assistência a mulheres em situação de violência, do trabalho do/a psicólogo/a para adequar a intervenção que lhe compete a partir do momento em que a violência é evidenciada e reconhecida como um problema, de intervenção que o enfrentamento da violência contra as mulheres demanda, da inserção do psicólogo na rede de assistência específica para o atendimento ou acompanhamento psicológico para a reestruturação da vida das mulheres nos Centros de Referência, nas Casas-Abrigo, nos Grupos de Reflexão sobre Masculinidades para homens autores de violência, e nos grupos de reflexão e construção de programas de Leitura Crítica da Mídia, na discussão das Questões de Gênero na Escola, e em tantos outros espaços em que o/as psicólogo/as possam prestar apoio emocional e acolhimento a mulheres vítimas da violência de gênero, doméstica, resgatando sua autonomia e fortalecendo sua autoestima,

Que mil ideias floresçam, e que possamos todos e todas crescer com elas!

\section{Referências}

A Tribuna. (28 de setembro de 2017). Trio é condenado por estuprar adolescente em balada de Santos. Recuperado de <https://goo.gl/TJGtxQ>

BBC News. (8 de agosto de 2011). "SlutWalk" marches sparked by Toronto officer's remarks. Recuperado de <http://www. bbc.com/news/world-us-canada-13320785>

Blogueiras Feministas (7 de agosto de 2017). 11 anos da Lei Maria da Penha. 11 dados recentes da violência contra a mulher no Brasil. Recuperado de <https:// goo.gl/HXWLve>

Broadcasting Ramires (2014). É menina! It's a girl 2012. (Arquivo de vídeo). Recuperado de <https://vimeo. com/100378967>

Caldeira, J. P. (21 de setembro de 2016). Um terço da população acha que a culpa é da vítima nos casos de estupro. Recuperado de <https://goo.gl/TJtZzu>

Compromisso e atitude Lei Maria Penha: a lei é mais forte. (2017). Dados e estatísticas sobre violência contra as mulheres. Recuperado de 〈https://goo.gl/yj1ZeH >

Forum Brasileiro de Segurança Pública e Data Folha. (2016). Percepção sobre violência sexual e atendimento às mulheres vítimas nas instituições policiais. Recuperado de 〈https://goo.gl/TvJWP3>

Guimarães, G., \& Prado, C. (28 de agosto de 2017). Por que é difícil para uma mulher perceber que seu parceiro é um agressor? Recuperado de 〈https://goo.gl/NtDtm2〉

Hirigoyen, M. F. (2009). Assédio moral - a violência perversa no cotidiano. Brasil: Editora Bertrand.

India's Daughter. (24 de setembro de 2015). India's Daughter. (Arquivo de Vídeo). Recuperado de <https:// www.youtube.com/watch?v=JoGtGv2KS48>
Instituto de Pesquisa Ecônomica Aplicada - IPEA. (2017). Atlas de Violência. Recuperado de <http://www.ipea.gov. br/atlasviolencia/download/2/2017>

Jornal O Povo Online. (15 de maio de 2016). Assédio contra mulheres. A violência que é rotina nas noites. Recuperado de 〈https://goo.gl/2u5Xkh>

Instituto de Pesquisa Ecônomica Aplicada - IPEA. (2017). Estupro no Brasil: uma radiografia segundo os dados da Saúde. Recuperado de 〈https://goo.gl/RRNe8v>

Justiça de Saia. (15 de maio de 2017). MPSP denunciou 31\% dos casos de feminicídio no país entre 2016 e 2017. Recuperado de 〈https://goo.gl/ghKrxF>

Justificando. (8 de junho de 2016). Cultura do Estupro: Justificando Entrevista Gabriela Mansur. (Arquivo de vídeo). Recuperado de <https://www.youtube.com/ watch?v=bU9yOFvZNbU>

Lins, B. A. (2016). Diferentes, não desiguais. São Paulo: Editora Reviravolta.

Marques, G. (6 de agosto de 2015). Criação da $1^{\mathrm{a}}$ Delegacia de Defesa da Mulher do país completa 30 anos. Recuperado de $\langle$ https://goo.gl/CCbboM>

Matsuda, N. F. (11 de março de 2015). Casa Eliane de Grammont, 25 anos: uma referência para mulheres em situação de referências. Recuperado de <https:// goo.gl/6hmUrf>

MM S. (12 de julho de 2013). A Guerra invisível. (Arquivo de vídeo). Recuperado de <https://www.youtube.com/ watch?v=M_yZ9ywEOMk\&feature=share $>$

Monteiro, E. A. (1 de julho 2017). Números mostram índice de violência contra a mulher no Brasil. Recuperado de <https://goo.gl/zuHk8q> 
Moreira, M. (3 de dezembro de 2014). Pesquisa mostra que $66 \%$ das mulheres foram vítimas de algum tipo de violência. Recuperado de <https://goo.gl/6og7Tv>

Moreno, R. (23 de setembro de 2016). Percepção sobre a violência sexual. Recuperado de <https://goo.gl/ b5K6yW>

Museu da Pessoa. (15 de junho de 2016). Desumanidades. (Arquivo de vídeo). Recuperado de <https://www. youtube.com/watch?v=NFPSS3qoWeU>

Nepomuceno, F. (19 de agosto de 2019). As justiceiras do Capivari. (Arquivo de Vídeo). Recuperado de <https:// www.youtube.com/watch?v=49pUMIPABBY>

Nos seins nous exposent - Le documentaire. (14 de junho de 2015). The breast ironed girls. (Arquivo de vídeo). Recuperado de <https://www.youtube.com/ watch?v=4Jw17QPf_vU>

Observatório de gênero. (2017). Enfrentamento de todas as formas de violência contra as mulheres. Recuperado de 〈https://goo.gl/Bt6oQL >

Olga. (2013). Chega de Fiu-Fiu. Recuperado de <http:// thinkolga.com/chega-de-fiu-fiu/>

Oliveira, F. (12 de julho de 2010). A lei “acariciou a onipotência” do goleiro Bruno. Recuperado de <https:// goo.gl/qr94KN>

O Tempo Cidades. (8 de setembro de 2013). Abordagens violentas na balada revoltam mulheres. Recuperado de <https://goo.gl/6cKa1k>

Popular TV Shows. (30 de setembro de 2016). A Girl In The River. (Arquivo de vídeo). Recuperado de <https://www. youtube.com/watch?v=B4ddvK3r7NU>

Radius. (21 de janeiro de 2015). The Hunting Ground. (Arquivo de vídeo). Recuperado de <https://www. youtube.com/watch?v=GBNHGi36nlM>

Rago, M. (7 de novembro de 2016). Insubmissão feminista. Recuperado de <https://goo.gl/Qz6fCT>

Ricchiardi, S. (6 de setembro de 2017). Cómo lidiar con el acoso online contra mujeres periodistas. Recuperado de <https://goo.gl/LtpzK9>
Secretaria de Politicas para as Mulheres. (2011). Rede de enfrentamento à violência contra as mulheres. Recuperado de <https://goo.gl/a8Fhkr >

Secretaria Nacional da Mulher Trabalhadora da CUT. (21 de setembro de 2016). A culpa do estupro NÃO é da mulher! Recuperado de 〈https://goo.gl/ZTZExd>

Sobre as violências contra as mulheres (2017). Violência doméstica e familiar. Recuperado de <https://goo.gl/ GExETd>

Soares, N. (7 de setembro de 2017). Em números: a violência contra a mulher brasileira. Recuperado de <https://goo. gl/FLPjdZ>

Souza, J. C. (15 de junho de 2016). Por uma cultura de respeito às mulheres. Recuperado de <https://goo.gl/ $\mathrm{v} 9 \mathrm{z} 7 \mathrm{mG}>$

Tiburi, M. (15 de dezembro de 2015). Sobre o feminismo e o papel da mulher. (Arquivo de vídeo). Recuperado de <https://www.youtube.com/watch?v=ZKwzGDH-468>

Time. (12 de agosto de 2011). A brief history of women's protests. Recuperado de <https://goo.gl/vsybrX>

Toda a verdade. (25 de novembro de 2015). Índia, um país que não gosta de mulheres. (Arquivo de vídeo). Recuperado de <https://www.youtube.com/watch? $=8 \mathrm{BhojKJSrD} 8>$

TV Brasil. (10 de junho de 2016). A cada 11 minutos, uma vítima. (Arquivo de vídeo). Recuperado de <https:// www.youtube.com/watch?v=UdhlxCrx9Pc $>$

Último segundo (2 de janeiro de 2018). Islândia agora é o $1^{\circ}$ país onde igualdade salarial entre homem e mulher é lei. Recuperado de <https://goo.gl/iVk1f4>

Vice. (23 de setembro de 2013). Ghost Rapes of Bolivia (Arquivo de vídeo). Recuperado de <https://www. youtube.com/watch?v=TSlc_Zib2nw $>$

World Economic Forum. (2015). The Global Gender Gap Report 2015. Recuperado de <http://reports.weforum. org/global-gender-gap-report-2015/>

Wikipédia. (17 de outubro de 2013). Femen. Recuperado de 〈https://pt.wikipedia.org/wiki/FEMEN> 